\title{
Tea Tree Oil
}

National Cancer Institute

\section{Source}

National Cancer Institute. Tea Tree Oil. NCI Thesaurus. Code C74295.

The essential oil extracted from the leaves of Melaleuca alternifolia. Tea tree oil is used for its antimicrobial properties. 